\title{
Curriculum Reform for Engineering Material and Forming Technology Course
}

\author{
Jingling Liing ${ }^{a}$, Hui Yang ${ }^{b}$ \\ Tianjin university of technology and education,Tianjin 300222, China \\ a28759400@qq.com, bYanghui@126.com,
}

Keywords: Experiment, practice training, Project-based teaching, team teaching, curriculum reform.

\begin{abstract}
Engineering material and forming technology course is a basic course, focuses on relationship of materials among composition, structure, properties and applications, as well as the forming process, which is closely association with the metalworking practice. Based on experiments and training, applying project teaching, team teaching, integrated engineering training project and other methods, this paper combines the two courses together. Theory with practice, create a 'theory-practice-innovation' integrated teaching system.
\end{abstract}

\section{Introduction}

With the development of strategy transformation in china, the training of applied talents are payed more and more attention to[1,2]. The engineering material and forming technology course is a basic course, which focuses on relationship of materials among composition, structure, properties and applications, as well as the forming process. This course is characteristic of comprehensive content, wide industrial application and closely association with the production. Combine this course with training of metalworking practice, according to the integrated teaching mode, the training content of Metalworking practice was introduced into the engineering material and forming technology course as teaching project, so as to solve its problem of engineering practice lack , and strengthening theory level of training course. That is propitious to the training of applied talents.

\section{Reform plan}

\subsection{Applying Project-based teaching method, to achieve "integration" teaching •}

Integrating engineering practice and innovation practice in to Theory teaching, The course of engineering material and forming technology was combined with metalworking practice. lectures will be interspersed with practical demonstrations. According to the Actual production process, we designed engineering training projects including heat treatment, microstructure observation, and forming process, and the training projects were introduced into the teaching.

When teaching Forming process module, abandon the teaching model of theoretical study before they are proven, integrated with engineering material and Metalworking practice.abandon the teaching model of theoretical study before they are proven, Students by doing tasks in the metalworking get perceptual knowledge, ask questions, come back to learning theory, after practice, to complete the task. That process form the project-based teaching to achieve learning and teaching by doing, focus on cultivating students ' ability of practice and innovation. Engineering practice teaching found on projects is based on the work processes, typical product or object involved as the carrier of the project, students learn in the process of completing tasks. Learning through completing engineering project, breaks the current job rotation metalworking plans in most colleges. Through the project student could learn about the true knowledge that required for the job. The project resources are of some tasks or actual products in industry, by filtering and optimization, the project resource are designed to be teaching project, and sent to all teams as study project. Each team would complete the task within the stipulated time, ratings and reviews. Each team is assigned a different project, the team must complete their own tasks and be responsible task of evaluating other team projects. In this way content 
duplication is avoided, also the the student could focus on and learning about tasks of other groups, to achieve the same effect. Before sending the project, explain on the corresponding process in the classroom and awareness training in practice, then the teacher teach the technological knowledge of process, student complete the task . After the task is completed, student practice. For some difficult task that can not be completed in training center during the training course, practice videos recorded in industry are applied in the classroom.

Design some integrated engineering training projects, in which the experiment of hardness test, he microstructure observation, heat treatment and forming process are associated with casting and forging process in Metalworking practice. Practice and experiment teaching is an important part in teaching process. Exploring multiple educational form and integrated teaching content to enhance the teaching effect help to cultivating students ' comprehensive ability. Take a low carbon steel part as an example, its manufacturing process include casting a blank, heat treating and then forging. This procedure covers the main knowledge of techniques and heat treatment in engineering material and forming technology course, also provide experimental subject for observation of microstructure changed before and after casting,forging, and heat treatment . Set this parts as practice object for casting and forging in metalworking practice, so that its casting and forging could be integrated with the forming process of engineering material and forming technology course. In this way, it avoids the repetition of the experiment of the two courses, and an enhances link of theory and practice.

\subsection{Promoting team teaching to enhance students interest in learning, cultivating a sense of teamwork.}

With the continuous improvement and upgrading manufacturing technology, modern industrial production of product combinations and complexity are increasing. This trend requires a team collaboration to complete processing by required quality and quantity[3]. Use team teaching method in teaching, both to stimulate students' interest in learning, promote the upgrading of teaching and to foster a sense of teamwork and ability[4]. Team is made up of two or more than two people, who come together for the common goal and assume responsibility for achieving this goal. the team's performance is based on each person's different roles and the effect size. Thus, team cooperation learning as advocated by the new curriculum reform of teaching mode and learning styles to our class has brought energy and hope, promote the reform and innovation of classroom teaching.

Specific methods are as follows.

1) In introduction class, Introduces students to the concept of teamwork, the team's value.By telling Fables and stories in the workplace, students take the team concept, and understand the importance of missions to the team, then can actively participate in the learning.

2) Forming the team and request. Forming the team according to principle of heterogeneity in a group and homogenization between groups. While students are required to complete the following tasks: elect a leader and an inspiring group, wrote the Panel the study Convention, establish group goals.

3) Set group race courses to enhance students ' interest in learning. Implementation of race points system in class, including awarded and deduct mark. Behavior Conducive to learning should be awarded . the opposite behavior would be deducted.

\subsection{Integrate theory and practice teaching with scientific research project.}

Starts with basic manufacture technique demand for engineering material, material forming and Manufacturing knowledge in modern engineering education[4]. Crossover and fusion of various disciplines are embodied in curriculum development, to implement innovative training combined with theoretical teaching and practical teaching[5].

Traditional course of engineering material and metalworking practice focus on manufacturing of metallic materials and practice. With the rapid development of science and technology, the updating of knowledge speed up, and specialty are largely adjusted. Dominance of the metallic materials gradually replaced by other engineering materials. Content is difficult to satisfy the curriculum needs for new materials, new processes and new technologies. Therefor, deleting the old knowledge, the main line of the course should be around the forming of engineering material instead of metal material. 
Teacher's scientific research in materials science and materials processing . the knowledge system can be fully expanded on the premise that curricular system is complete,To integrate the theory, practice, innovation and educational links.

\subsection{Teaching evaluation}

Periodically to evaluate the team groups, the assessment results are as a part of the course grade. In this course, each student's grades consist of the following parts: experiment grade(30\%), daily assignment(20\%), Team accomplishments(30\%) and score given by group leader(30\%).

\section{Summary and Outlook}

The course of engineering material and forming process is integrated to the metal working practice , to integrate the system of experiment, training and theory course,

And for integration of theory with practice in the teaching mode. That is helpful to the cultivation of engineering ability. Of the student. In the process of implementation,there are some problem which need to be solved in subsequent further reform.

1 ) Teaching project need further optimization and integration.

2 )New curriculum requires teachers to have "integration" teaching ability. Therefor, we should make efforts to the training of 'integration' teaching .Summary

If you follow the "checklist" your paper will conform to the requirements of the publisher and facilitate a problem-free publication process.

\section{Acknowledgments}

Supported by Tianjin higher school undergraduate teaching quality and teaching reform project NO:C03-0802

\section{References}

[1]. Zhangxiao Zhu, engineering material[M], Qinghua University Press,2010

[2]. Wei Zhao, Wenping Zhao. Study on single-chip microcomputer course construction based on matrix [j]. Vocational and technical education. 2014. (10): 91-93

[3]. Lumsden,G., Group and team communication,.[M]. Feng Yunxia translation.Machine press 2001.

[4]. Yongfeng Cai. On the application of team cooperation learning in college English teaching [j].China's school education 2008 (3).

[5]. Ying Cui. Study on the construction of curriculum system in universities [j]. Exploration of higher education. 2009. 3:88-90 